\title{
A singularidade da dor de pacientes oncológicos em cuidados paliativos
}

\author{
Vitória Cordovil de Almeida* \\ Elvira Silvestre Chaves Gama** \\ Cristian Ariel Neira Espejo*** \\ Janari da Silva Pedroso****
}

\section{Resumo}

A dor tem sido estudada nas diversas áreas da saúde, mas deve ser compreendida em uma perspectiva multidimensional que inclui os aspectos sociais, espirituais e psíquicas. O objetivo deste estudo foi compreender a vivência da dor crônica de pacientes oncológicos que estão em tratamento paliativo. Trata-se de pesquisa qualitativa com uso de entrevista e diário de campo. Os dados foram sistematizados a partir da análise de conteúdo, que originou a categoria temática: a singularidade da dor, os modos de enfrentamento e história clínica das participantes internadas em um Hospital Público na Clínica de Cuidados Paliativos Oncológicos. Os dados sinalizam que a religiosidade, espiritualidade e a dificuldade em falar da dor e deparar-se com ela foram os modos pelos quais as participantes narraram suas dores e o processo de adoecimento. A escuta em um ambiente em que o sujeito se sinta acolhido permite falar da dor por meio das palavras ou do silêncio.

Palavras-chave: Cuidados Paliativos; Paciente Oncológico; Dor; Subjetividade.

\section{The singularity of pain in cancer patients on palliative care}

\begin{abstract}
The pain has been studied in the various areas of health, but it must be understood in a multidimensional perspective that includes social, spiritual and psychic aspects. The objective of this study was to understand the experience of chronic pain in cancer patients undergoing palliative treatment. This is a qualitative research using interview and field diary. The data were systematized based on content analysis, that originated the thematic category: pain singularity and coping modes and clinical history of the participants hospitalized in a Public Hospital at the Oncology Palliative Care Clinic. The data indicate that religiosity, spirituality and the difficulty in talking about and encountering pain were the ways in which the participants narrated their pain and the process of illness. Listening in an environment where that the subject feels welcomed allows to speak of pain through words or silence.
\end{abstract}

\footnotetext{
* Psicóloga especialista em Oncologia e Cuidados paliativos pela UEPA - Hospital Ophir Loyola, Preceptora do programa de residência multiprofissional em cancerologia do Hospital Erasto Gaertner e Especialista em saúde mental e psicanálise pela PUC-PR.

** Mestre em Psicologia pela UFPA, especialista em Psicologia hospitalar. Psicóloga, tutora e preceptora do Programa de residência multiprofissional em Oncologia e cuidados paliativos hospital Ophir Loyola - UEPA.

***Psicólogo Universidad de las Américas e Mestrando na UFPA.

****Psicólogo Pós-Doutorado UCB, Doutor e Mestre pela UFPA e Professor associado da UFPA. Bolsista Produtividade CNPq.
} 


\section{Introdução}

O paciente acometido de câncer em estágio avançado apresenta várias peculiaridades frente ao adoecimento que diferem do enfrentamento de outras doenças. De acordo com Barbosa e Francisco (2007), o câncer ainda é uma doença estigmatizada em nossa sociedade causadora de medo e dor. Os pacientes normalmente convivem com dor em virtude dos tratamentos utilizados, condição clínica e localização da neoplasia. Quando o câncer se encontra em estágio avançado, 65 a $85 \%$ dos pacientes sentem dor (Naime, 2013).

As dores em pacientes oncológicos são mais intensas e dificilmente controláveis, sendo necessário que eles convivam com ela em algum momento do dia ou em níveis intensos e constantes, fenômeno este conhecido como dor crônica ou refratária (Miceli, 2002). A dor é o sintoma mais temido da doença, frente às fantasias de que ela seja terrível e incontrolável (Pimenta, Koizumi e Teixeira, 1997). Portanto, há necessidade de abordar a dor em uma perspectiva dos cuidados paliativos para uma compreensão subjetiva.

A dor está presente na vida do sujeito acometido com câncer quando esta doença evolui para um estágio avançado. A abordagem paliativa entra em cena para o manejo e controle de sintomas, para cuidar dos aspectos psicossociais e do processo de adoecimento (INCA, 2015).

Sobre a dor e os Cuidados Paliativos a Organização Mundial de Saúde - OMS se posiciona desde a década de 80: em 1980, a OMS elegeu como emergência médica mundial o tratamento da dor de pessoas com neoplasias (Graner, Junior \& Rolim, 2010). Em 2002, definiu Cuidados Paliativos como a assistência realizada por uma equipe multiprofissional que visa melhorar a qualidade de vida do paciente e seus familiares e possibilitar o alívio de sintomas decorrentes do processo de adoecimento frente a uma doença que ameace a continuidade da vida (WHO, 2002) e em 2004 o alívio da dor passou a ser um direito humano.

A dor oncológica é uma expressão utilizada para definir a dor em pacientes oncológicos e se caracteriza pela junção de múltiplas etiologias (tratamento, infiltração neoplásica, localização do tumor) que, juntas, se potencializam (Thomaz, 2010). Estes fatores podem estar relacionados ou não ao câncer. A Sociedade Brasileira para o Estudo da Dor - SBED (2015) afirma que a dor no câncer talvez se apresente como o modelo mais complexo de dor, por conter distintas origens, como a doença e seu prognóstico, o tratamento e morbidades associadas.
Atualmente, a dor não é apenas um fenômeno físico circunscrito ao corpo, por isso a importância dos aspectos multifatoriais também serem levados em consideração. A abordagem multidimensional da dor foi elaborada por Saunders (1967), que cunhou o conceito "Dor Total" para identificar a dor em seus níveis sociais, somáticos, espirituais e psicológicos (Naime, 2013).

Os aspectos somáticos da dor seriam os tipos de neoplasia, lesões iatrogênicas e patologias preexistentes. Do ponto de vista social, a dor estaria vinculada aos relacionamentos familiares - cuidados e sexualidade -, problemas financeiros, medo da dependência, relacionamentos com amigos. Psicologicamente os sentimentos de culpa, medo, ansiedade e depressão estariam envolvidos na dor psíquica e, na esfera espiritual, problemas relacionados à morte e ao morrer, à liberdade e ao amor (Saunders, 1967).

No processo de agravamento da doença observa-se a influência do tipo de personalidade e sua história de vida. Ao adoecer, o paciente se depara com algumas perdas, como: afastamento da família, do trabalho, perda da autonomia e consequente dependência de terceiros nos cuidados consigo mesmo. Estas perdas estas envolvem dor, degeneração e medo do sofrimento (Kovács, 2003).

O paciente pode enfrentar algumas dificuldades diante da nova realidade imposta pelo adoecimento, como a alteração da rotina diária, dependência de cuidados de terceiros, mudança de hábitos, alteração da imagem corporal e isolamento social (Santana, Zenin \& Maniglia, 2008). Ao deparar-se com este novo contexto biopsicossocial o paciente pode vir a apresentar sofrimento psicológico, evidenciado pelos sintomas de depressão, ansiedade, pensamentos de desesperança, medo e incerteza relacionada ao futuro.

\section{Breve história sobre o estudo e tratamento da dor}

A palavra "dor" origina-se do latim dolore, cujo significado atribui-se a padecimento, sofrimento. Ela tem um papel fundamental na vida do homem, para protegê-lo de algum dano físico iminente e para reparar o dano já existente. Com o objetivo de controlar e estudar a dor, ela passou a ter um universo de significados para os seres humanos na ciência médica, na antropologia e na história (Salgado \& Salgado, 2013).

Assim, o estudo cultural da dor salienta três manipulações mais conhecidas, que são os ritos de passagem, o cilício e a tortura (Salgado \& Salgado, 2013). Até meados do século XIX, sob a influência da Igreja Católica, a dor 
representava um martírio fundamental para a expiação dos pecados dos homens e servia como instrumento de coerção política, social e religiosa, utilizando-a como recurso de punição e inibição dos indivíduos e da sociedade (Miceli, 2014).

Durante o percurso para o controle da dor e do sofrimento humano, a história da dor mistura-se com a história dos medicamentos ministrados, para atenuar ou extirpar o martírio físico (analgésicos) ou com o objetivo de suprimir qualquer sensação (anestésicos). O século XIX demarca o período em que os analgésicos e anestésicos tiveram seu preparo purificado, em virtude da indústria química, mas, segundo os historiadores da medicina, eles já existiam na medicina antiga (Salgado \& Salgado, 2013).

No século XIX, os estudos sobre a morfina se desenvolveram e os opióides foram manipulados. A dor física, então, passou a ser estudada, separando-a, deste modo, do sofrimento social. Na virada dos séculos XIX e XX, a dor passou a ser compreendida como um fenômeno biológico, fisiologicamente explicado.

Para sistematizar o estudo da dor, em 1973, foi fundada a International Association for the Study of Pain (IASP), a qual postula que "dor é uma desagradável experiência sensorial e emocional que se relaciona a uma lesão real ou potencial dos tecidos, ou ainda descrita em termos deste dano" (SBED, 2015).

De acordo com Pessini (2004a), há dois tipos de dor, a aguda e a crônica. A dor aguda se relaciona a algum tipo de lesão corporal e tende a desaparecer assim que esta minimiza. A dor crônica associa-se a um período superior a seis meses, com duração que vai além do tempo esperado para a cura de uma lesão. É uma dor contínua, que pode retornar em intervalos de meses ou anos.

A SBED (2015) aponta que a dor pode ser compreendida como um fenômeno multidimensional, que facilita intervenções multidisciplinares no manejo clínico de cada paciente. As pessoas de modo geral apresentam dificuldades em descrever sua própria dor e falar da dor do outro é ainda mais inatingível, e isto se dá em virtude de a dor ser uma experiência individual, com características próprias de cada sujeito: cultura, história de vida, vínculos sociais, que envolve componentes afetivos, sensoriais e comportamentais (Guimarães, 1999).

A dor pode apresentar diversas características, que são: localização, qualidade, intensidade, frequência, natureza, etiologia e duração. A localização da dor pode dar-se nos músculos, pele, dentes ou em membros amputados, que se caracteriza como a dor fantasma. A localização pode ser pontual e bem definida ou difusa e de difícil identificação. Compreende-se como qualidade da dor a principal sensação que ela ocasiona, como formigamento, queimação, latejamento, pontada, ardor, dentre outros. A intensidade da dor pode ser notificada como forte, fraca, insuportável e sem dor (Guimarães, 1999).

Ainda para esta autora, a frequência da dor pode ser compreendida como ininterrupta ou episódica, podendo surgir em intervalos de tempo distintos. A natureza da dor pode ser orgânica, fisicamente reconhecida ou psicogênica, sem causas físicas e relacionada ao funcionamento ou momento psicológico da pessoa. A etiologia caracteriza o modo desencadeante da dor: fratura, cirurgia, artrite, acidente químico, dentre outras. Por fim, a duração da dor é definida como um episódio doloroso, podendo permanecer por diferentes períodos de tempo, variando em meses ou anos (Guimarães, 1999).

As dores oncológicas representam 5\% das dores crônicas no mundo e há uma estimativa de que 18 milhões de pessoas apresentam câncer diagnosticado atualmente, sendo a dor um problema comum nestes pacientes. Elas ainda não têm sido controladas de maneira adequada em virtude das avaliações imprecisas do quadro da dor e má utilização dos recursos antiálgicos disponíveis (Pessini, 2004a).

No Brasil, as pesquisas sobre dor ainda não possuem investimento considerável na assistência à saúde. De acordo com Carvalho (2002), no processo de adoecimento oncológico a dor geralmente está presente, seja pela doença, pelos tratamentos dolorosos. A dor no câncer pode ocorrer devido às lesões orgânicas, além dos aspectos psicológicos e do significado dado a ela por cada indivíduo. Por isso, programas de educação sobre a dor em pacientes oncológicos são necessários para melhorar esta problemática para doentes, familiares, profissionais da saúde e todos que, de algum modo, estão voltados para os cuidados em saúde (Pessini, 2004).

$\mathrm{O}$ autor propõe que estes programas de educação devem ser fundamentados em alguns princípios norteadores, que são 1) visão da dor nas suas diferentes dimensões; 2) valores éticos e a importância da qualidade de vida e 3) presença de equipe multidisciplinar. Uma vez que a dor engloba aspectos biológicos, emocionais e culturais de um sujeito, a indivisibilidade desses valores precisa ser considerada nas intervenções terapêuticas, atuando na causa da dor (Pessini, 2004a).

Com relação aos valores éticos e a importância da qualidade de vida, o autor aponta que "o respeito pela dignidade do ser humano, bem como sensibilidade no processo de tomada de decisões terapêuticas, devem per- 
mear toda a atividade de ensino, pesquisa e assistência" (Pessini, 2004, p. 17). Deste modo, é importante que profissionais dos cuidados em saúde estejam disponíveis para valorizar a qualidade de vida do indivíduo adoecido e fragilizado pela dor e pelo sofrimento.

Observa-se a importância da equipe multidisciplinar nos programas de educação para a dor em pacientes oncológicos. A assistência multidimensional possibilita a melhor compreensão dos conceitos que envolvem a dor e as diversas esferas de manejo clínico (Pessini, 2004). No Brasil e em países desenvolvidos, a dor não é adequadamente avaliada e controlada, por haver, dentre outros fatores, a subestimação do sofrimento, a crença de que em alguns casos a dor já está incontrolável ou o receio de que o paciente desenvolva dependência e tolerância as medicações analgésicas. São esses os motivos para a criação dos centros multidisciplinares para o tratamento da dor (Teixeira, Figueiró, Yeng, \& Pimenta, 1999).

Deste modo, a interação de vários aspectos do sujeito - físicos, cognitivos, emocionais, sociais, culturais e espirituais - demandam um olhar global sobre o mesmo, no qual oncologista, neurologista, assistente social, psicólogo, enfermeiro, terapeuta ocupacional e clérigo serão membros da equipe de assistência ao paciente com dor e sofrimento (Carvalho, 2002).

A atuação do psicólogo na equipe dos Cuidados Paliativos apresenta algumas características peculiares. Uma vez que os saberes psicológicos se dão a partir da compreensão do fenômeno como pertencente ao campo da mente, das vivências e das expressões dela pelo corpo, e cabe ao psicólogo promover uma assistência harmônica (Ferreira, Lopes \& Melo, 2011).

O psicólogo, neste processo de adoecimento do sujeito é um ouvinte privilegiado (Simonetti, 2011) no contexto dos cuidados paliativos, para que pacientes oncológicos tenham um espaço de fala, acolhimento de suas demandas psíquicas e alívio do sofrimento durante o processo de hospitalização e adoecimento. Entrar em contato com aspectos subjetivos relacionados à dor para poder simbolizá-las e utilizar recursos de enfrentamento diante dos impactos causados por ela é, sem dúvida, um lugar acolhedor e seguro para o sujeito se apoderar e tornar senhor de suas próprias questões.

Em cuidados paliativos, o psicólogo deve detectar os conteúdos envolvidos no discurso do paciente, no sintoma e na patologia e o que está para além disso, para oferecer atendimento integral ao indivíduo e, desta forma, identificar as desordens psíquicas que podem gerar sofrimento, estresse, mecanismos de defesa, dentre outras intercorrências (Ferreira, Lopes \& Melo, 2011)

Acredita-se que estudos e pesquisas nessa área são importantes para se discutir e analisar a realidade subjetiva de cada sujeito que vivencia o câncer em cuidados paliativos, assim como a contribuição para a psicologia hospitalar e suas diversas formas de atuação. Portanto, o objetivo deste estudo foi analisar a vivência da dor de pacientes oncológicos em tratamento paliativo que apresentam dor crônica.

\section{Método}

Este estudo baseou-se em um modelo de pesquisa qualitativa para compreensão dos valores, hábitos, representações, opiniões dos participantes que são importantes pela complexidade de fatos e processos de cada indivíduo (Minayo \& Sanches, 1993). A subjetividade e o simbólico são elementos fundamentais da pesquisa qualitativa, por apostarem na ideia de que estes fazem parte da realidade social do ser humano e da coletividade (Minayo, 2014).

Ao se adotar o modelo de pesquisa qualitativa em psicologia, o processo de investigação torna-se complexo, por ser um procedimento construtivo-interpretativo. A metodologia qualitativa compreende a ciência como a construção da subjetividade humana, na qual a investigação se dá dentro do fenômeno estudado, havendo interferências no objeto, o que impossibilita a neutralidade. A Psicologia é uma ciência humana complexa que se altera sócio-historicamente por influências internas (dos indivíduos) e externas (da cultura e do meio social) (Pinto, 2004).

\section{Participantes}

A amostra desta pesquisa configurou-se como de conveniência e não possuiu caráter estatístico. Foram duas pacientes internadas em uma Clínica de Cuidados Paliativos Oncológicos, maiores de 18 anos que estavam em condições clínicas de participar da pesquisa. Elas estavam conscientes, orientadas no tempo e no espaço, contactuantes e com capacidade de manter comunicação verbal. As participantes foram identificadas com pseudônimo, voluntárias e convidadas a participar da pesquisa mediante esclarecimentos dos objetivos e seu consentimento definido pela Comissão Nacional de Ética em Pesquisa (CONEP), conforme Resolução 466/2012 do Conselho Nacional de Saúde e 016/2000 do Conselho Federal de Psicologia. 


\section{Local da pesquisa}

O estudo foi realizado em uma Clínica de Cuidados Paliativos Oncológicos com quatro enfermarias, sendo duas com 2 (dois) leitos e duas com 3 (três) leitos. As enfermarias que apresentam três leitos são divididas em feminina e masculina, cada uma comportando 3 (três) homens e 3 (três) mulheres separadamente. Neste mesmo espaço, cada paciente internado tem direito a um acompanhante.

\section{Instrumentos}

\section{Entrevista semiestruturada}

Foi criado um roteiro de entrevista que buscou compreender a vivência da dor destas pacientes. Esta entrevista semiestruturada apresentava tópicos que serviram de guia para o entrevistador da pesquisa. Este modelo, proposto por Minayo (2014), deve permitir a flexibilidade nas conversas e a absorção de outros temas e questões vindos do interlocutor que apresentam importância para o mesmo.

Nesta pesquisa, os tópicos estavam voltados para a compreensão de como o paciente oncológico em cuidados paliativos com dor crônica experiencia sua dor e quais as repercussões desta em sua vida e no atual momento de internação hospitalar.

\section{Diário de campo}

Para que a pesquisa captasse dados de observação e se tornasse mais rica de detalhes e de momentos extra formais, optou-se pelo diário de campo. Nele, o pesquisador anota todas as informações e, inclusive, as observações sobre "conversas informais, comportamentos, cerimoniais, gestos, expressões que digam respeito ao tema da pesquisa” (Minayo, 2014, p. 194). Deste modo, dia após dia, o investigador registrou também suas impressões pessoais que foram se alterando ao longo do tempo, preservando a identidade dos autores alvos de sua escrita, bem como escrevendo de modo coloquial o que surgia como reflexões e possibilidades de diálogo com o leitor deste trabalho.

\section{Materiais}

Os materiais para coleta de dados da pesquisa apresentaram, como finalidade, a capacidade de registrar fenômenos ao redor dos objetivos definidos na pesquisa. Neste estudo, foram utilizados como materiais: folhas sem pauta, com as entrevistas semiestruturadas impressas; lápis e canetas esferográficas, para o registro das informações biopsicossociais contidas nos prontuários dos participantes, assim como para a transcrição das respostas destes durante o momento da aplicação das entrevistas; um caderno de anotações (diário de campo), para o pesquisador anotar suas impressões durante o tempo da pesquisa na clínica e gravador de áudio mp3 usado com a permissão do paciente.

\section{Procedimentos}

Para que a participação das pacientes na pesquisa fosse possível, algumas etapas éticas foram necessárias. Primeiramente, o pesquisador investigou em prontuários e com a equipe da Clínica de Cuidados Paliativos Oncológicos (CCPO) quais os pacientes apresentavam dor refratária crônica e que estariam de acordo com os critérios de inclusão descritos nesta metodologia. Foram eleitos duas pacientes que, após a explanação dos objetivos da pesquisa, aceitaram participar. Após o aceite dos colaboradores, que assinaram o Termo de Consentimento Livre e Esclarecido, foram feitas as entrevistas semiestruturadas. Estas foram realizadas nos leitos das pacientes para que o sigilo e a privacidade fossem garantidos.

\section{Análise de Dados}

Para a análise de resultados das entrevistas semiestruturadas, foi utilizada a Técnica de Análise de Conteúdo proposta por Bardin (2011). Definida como um conjunto de técnicas de análise das comunicações que analisa o conteúdo das mensagens em três fases: Pré-análise; Exploração do Material e Tratamento dos resultados, inferência e interpretação.

$\mathrm{Na}$ pré-análise realizou-se a organização do material coletado pela entrevista e a transcrição desta, realizando leitura flutuante: "pouco a pouco, a leitura vai se tornando mais precisa, em função de hipóteses emergentes, da projeção de teorias adaptadas sobre o material” (Bardin, 2011, p. 126). Após análise das falas, houve a seleção do material para análise, para que questões concordantes com os objetivos da pesquisa fossem consideradas. $\mathrm{Na}$ fase de exploração do material, ocorreu a codificação dos dados, organizando-os em unidades ou descritores do mesmo conteúdo relatado nas entrevistas. Estes descritores e categorizações foram as características principais do conteúdo.

\section{Resultados e Discussão}

\section{A história clínica de Elis}

Elis, 71 anos, católica, separada, mãe de sete filhos, agricultora aposentada, estudou até a quarta série do 
ensino fundamental e foi admitida pela primeira vez no Hospital em 1989, quando foi diagnosticada com câncer de colo do útero. Realizou três procedimentos terapêuti$\cos$, quais foram a quimioterapia (QT), radioterapia (RT) e braquiterapia. Elis não realizou procedimentos cirúrgicos para tratamento, como histerectomia total ou parcial.

De acordo com os registros do prontuário, atravessou muitos anos apresentando dor intensa e persistente em membros inferiores e região pélvica. Em outubro de 2013, verificou-se que Elis tinha abandonado o tratamento há 06 anos, ou seja, sua última presença no serviço foi em 2007. Elis retornou por conta da recidiva da neoplasia e tratou com quimioterapia. Em julho de 2014, a equipe médica realizou a conduta de encaminhá-la para a Clínica de Cuidados Paliativos Oncológicos (CCPO).

Internou com caquexia neoplásica, dores intensas em membros inferiores e região pélvica, urostomizada e com fístula reto-vaginal. Comunicativa, consciente e orientada no tempo e no espaço e fazendo uso de medicações para analgesia, Dipirona (Metamizol sódico) e Dimorf (Morfina).

Em setembro de 2016, relatou melhora do quadro álgico e de acordo com registros estava sorridente e conversando. Dia sete de setembro a algia retornou de modo intenso no quadril e membros inferiores. Dia nove, o bem estar de Elis é perceptível pela equipe e não há queixas de dor. Dia 21 de setembro, a dor estava parcialmente controlada. No dia 25, Elis estava pouco responsiva. Nos dias que se seguiram, Elis ficou menos contactuante, em sedação paliativa e, dia 28 de setembro, evoluiu a óbito.

\section{A história clínica de Ana}

Ana, 33 anos, católica, solteira, estudou até a oitava série do ensino fundamental, desempregada, foi assistida pela primeira vez no ambulatório do Hospital em 2014, quando recebeu o resultado histopatológico de lesão em colo do útero.

Realizou quimioterapia e 35 sessões de radioterapia, de outubro de 2014 a fevereiro de 2016. Chegou a ser internada na Urgência oncológica com náuseas e dor pélvica. Ao longo da internação e do atendimento ambulatorial, Ana referiu dor intensa em região pélvica. Em julho, a dor persistia na mesma região e pela segunda foi internada em outubro de 2016. A queixa dela era principalmente sangramento vaginal e apresentava quadro de dor intensa, mesclando-se a indisposição, sonolência, dor nas costas e nos membros inferiores. Bastante sonolenta, pouco contactuante, o quadro de Ana agravou-se e em função deste quadro clínico entrou em sedação paliativa e evoluiu para óbito.

\section{Singularidade da Dor: Modos de Enfrentamento}

Desde o tempo hipocrático há registros sobre a influência da espiritualidade no combate ao sofrimento humano. Como nos diz a epígrafe de Hipócrates (460 a. C. -370 a. C), amenizar a dor é obra divina. A espiritualidade e questões vinculadas com o sentido da fé têm sido inseridas nos cuidados aos pacientes com câncer em estágio avançado (Breitbart, 2004). Ana, ao ser questionada como enfrenta a dor, respondeu:

"Muita luta... Só Deus... [pausa] Deus na minha vida. [silêncio] Sem Ele, a gente não ia suportar, né, as dores... Dói muito [pausa]... A gente quer lutar, né... Eu sinto muita dor, muita dor mesmo... Tentar... Ter fé... [pausa] Tá bom. (Ana)"

Ana deixou nítida a importância da espiritualidade nesse momento de sua vida, ao dizer que só dá conta de suportar as dores com a presença de uma entidade superior à humanidade que, para ela, é Deus. Uma vez que a cultura ocidental é submersa na crença religiosa judaico-cristã, Deus se apresenta como elemento que ameniza o sofrimento humano, passando a ser senhor da saúde e da doença (Faria \& Seidl, 2005). Para Ana, se apegar a um Deus e ter fé são tão importantes quanto aderir à medicação para analgesia. Os aspectos religiosos e espirituais têm feito parte da adaptação ao diagnóstico e tratamento de câncer (Veit \& Castro, 2013).

Para Berlinck (2011), “a busca da vida eterna pela religião é, de fato, aquilo que retira o humano de sua infinita tristeza" (p. 423). Ana, investida em sua dor, recorre à Deus para tentar sanar sua amargura. Como ela diz, a gente quer lutar, mas nos parece uma luta solitária e pequena caso não conte com Deus. Ana precisa apoiar-se em uma esfera transcendental, com fé e esperança, para aliviar seus sintomas álgicos.

Elis, mergulhada em perdas amorosas, saudade e sorrisos, optou, ao longo de seu percurso, por não gritar a dor. Como na música de Charlie Chaplin cantada por Djavan, "Sorri / Vai mentindo a tua dor / E ao notar que tu sorris / Todo mundo irá supor / Que és feliz", Elis mente sua dor na medida em que sorri para seus familiares, para a equipe do hospital, como registrado no prontuário : sorridente e conversando. A a palavra é fundamental no campo da Psicanálise para adentrar ao campo do inconsciente do sujeito, com o objetivo de ajudá-lo a entrar em contato com suas questões e sintomas (Fuchs \& Zorning, 2013). Contudo, quando ocorre de o sujeito vivenciar experiências 
traumáticas e psiquicamente desorganizadoras, nem sempre as palavras darão conta desse lugar, entrando em cena o silêncio e o não verbal do corpo.

Elis, anterior à esta entrevista, pouco comunicara sua dor à equipe a aos seus familiares. Quando lhe foi permitido falar sobre essa dor, ela descarregou com toda intensidade a dor outrora silenciada:

"Eu sinto dor, muita dor, mas nunca gritei. Eu sinto, eu sofro, é... Eu sofro dor, dor, dor, dor, dor, dor, dor, dor, mas eu não grito... Nem aqui [hospital] nem na casa da minha filha. É... Eu fico sentindo aquela dor, mas não grito, não... Pra mim é melhor... Eu ficar sem ela. Que ela suma de uma vez, saia de mim... É... Me deixe... Me deixe ficar (...) porque a minha saúde é que eu quero. É... É isso. (Elis)"

Neste trecho é claro o sofrimento de Elis diante da dor e o quanto ela evitara falar de seu quadro álgico. A entrevista, para ela, então, foi um momento libertador, por ter permitido a descarga de afetos embotados (Fuchs \& Zorning, 2013) e, quem sabe, a simbolização dessa dor guardada, transmutada em relações amorosas frustradas, lágrimas pela saudade de seu lar, impedimento da vida pelo adoecimento. Nasio (2008) afirma que a defesa contra a dor da comoção dói ainda mais, pois “à dor própria do transtorno se acrescenta outra, a que exprime o esforço desesperado do eu para salvar a sua integridade" (p. 46). Elis defendia-se da dor, protegia-se contra a possibilidade de uma morte próxima?

Tanto em Ana como em Elis, podemos estender nossa compreensão sobre a dor e tê-la como sinônimo de morte, uma vez que ambas sabiam de seus diagnósticos e sobre a finalidade do tratamento em cuidados paliativos. Dantas (2013), ao falar sobre dor e fazer sua relação com a morte, afirma que o ser humano escamoteia a verdade sobre a morte e a dificuldade em darmos sentido ao processo de morrer. Em ambos os discursos das participantes, há o embate entre o desejo de continuar vivendo e as nítidas e irreparáveis perdas do agravamento da doença e da proximidade da morte. Dantas (2013) afirma que a última dor - que se encontra na figura da morte - é um momento de pesar, soturno, de despedidas e luto.

Elis e Ana estavam vivenciando as perdas da saúde, das possibilidades de movimentação do corpo, das atividades ocupacionais, do afastamento da família e a inexorável solidão frente os sintomas álgicos. Freud (1915/2010), em Considerações atuais sobre a guerra e a morte, afirma que considerar a própria morte é inconcebível: "manifestávamos a inconfundível tendência de pôr a morte de lado, de eliminá-la da vida. Procurávamos reduzi-la ao silêncio" (p. 230). Apesar de entrarem em contato diariamente com a morte, Elis e Ana apresentaram tal dificuldade frente às suas próprias mortes, intrínseca à natureza humana.

Este impasse e o silêncio diante do processo de morrer podem ser explicados pelo fato de que "no inconsciente cada um de nós está convencido de sua imortalidade" (Freud, 1915/2010, p. 230). Deste modo, Ana e Elis, a seu modo, conseguiram rondar a morte, pranteando dores, elaborando lutos antecipatórios, clamando por um momento sem dor e com esperança de dias melhores.

Outro discurso que nos revela a morte em outras palavras é quando Elis diz não querer que a dor a leve: "que ela [a dor] suma de uma vez, saia de mim (...) Me deixe ficar". Ela pedia para ficar encarnada e sem dor, porque esta talvez a levasse para outro lugar que não seja palpável, a direcionaria para a morte.

Neste apelo, observamos que a esperança ainda se fazia presente em sua vida. Talvez tenha sido uma forma de negação temporária, contudo, necessária para dar continuidade na vida com menos sofrimento (Kübler-Ross, 2008). Ainda para esta autora, quando o paciente não revela sinais esperança, possivelmente é um prenúncio de morte iminente.

Ana e Elis, diante de um vasto espectro de fragilidades de ordem física, psíquica, social e espiritual, precisavam ter um lugar para dar vazão a essas dores que nos pareceram irremediáveis e que nem a maior quantidade de Dimorf $₫$ daria conta de tanta angústia. Castro-Arantes e Lo Bianco (2013) reafirmam a importância do psicólogo neste processo:

\footnotetext{
"Não há cura, não há garantia, há fragilidade, desamparo e solidão. A aposta é a de que o sujeito possa sofrer isso não tão sozinho. Encontrar alguém a quem endereçar a sua palavra pode ter como efeito tomar o real (do câncer, do corpo, da morte) com os recursos dados pelo simbólico (da palavra, do significante, da construção da história do sujeito), o que terá feito elaborar minimamente algo do horror que o atinge (Castro-Arantes \& Lo Bianco, 2013, p. 2521)."
}

Em um lugar de ouvinte, pesquisadora e psicóloga, oferecer a elas um espaço de escuta continente e de acolhimento de suas demandas psíquicas foi a minha constante tentativa. Inicialmente, ressoou como algo do- 
loroso, por atentar a dor do outro e, consequentemente, a minha própria dor.

Sem hesitar, ela [Ana] me respondeu com um "Com certeza!" em alto e bom tom. Ainda que ela topasse participar de um modo tão seguro, eu fiquei preocupada em chegar, perguntar sobre sua dor. Por outro lado, ainda continuo pensando e acreditando na importância de dar vazão a este desconforto através da fala, para ser acolhido, jogado para fora e, quem sabe, ser ressignificado... Ou materializado em palavras. Com essas dúvidas e entraves, questiono-me constantemente sobre o meu lugar enquanto pesquisadora (Notas do diário de campo, dia 07 de outubro de 2016).

Penso que a neutralidade de fato é quase impossível em um campo onde a subjetividade impera, onde o sofrimento grita e onde os questionários são muito mais que perguntas (...). Eles são disparadores de sentimentos, fantasias, medos, expectativas e faltas, afinal, falar de dor é sinal de que falta o bem estar, falta a saúde, falta a serenidade... Falta (Notas do diário de campo, dia 19 de outubro de 2016).

A impossibilidade de neutralidade, a preocupação em falar da dor, o constante questionamento da importância deste lugar também são formas de enfrentar a dor - agora do lado do pesquisador - e falar dela. Segundo Nasio (2008), é nossa experiência singular na dor que nos inscreve como sujeitos na sociedade e na história. Enfrentar a dor alheia de outro lugar, do campo de quem escuta e procura ganchos para auxiliar na elaboração do sujeito, faz com que tenhamos o olhar de que é preciso continuar falando de dor, torna-la materializável, ou não, conforme seu autor a desejar.

\section{Considerações Finais}

A filosofia dos Cuidados Paliativos no Brasil se fortalece a cada década e contribui no campo da saúde para a compreensão da necessidade da melhora da qualidade de vida de pessoas com doenças crônicas como é o caso do cancêr. As pessoas são acometidas por doenças que ameacem a continuidade da vida e podem ser tratadas de forma digna durante todo o processo de adoecimento. Neste sentido, o cuidado integral ao sujeito é um dos principais pilares e visa à atenção ao paciente $\mathrm{e}$ seus familiares, a compreensão da morte como processo natural da vida, sem pretensões de adiar ou antecipar a morte. Também inclui cuidar dos sintomas decorrentes do agravamento da doença, como a dispneia, a astenia, edemas, insônia e a dor.
O câncer, em seu estágio avançado ou em metástase, pode ocasionar dor no sujeito, sendo de diversas naturezas, graus e intensidade. Contudo, o paciente que sofre dor crônica, dificilmente terá sanada sua dor apenas com os tratamentos medicamentosos, com opioides e demais medicações para analgesia. A ciência farmacológica tem buscado avançar nos estudos para dar conta das dores decorrentes do câncer avançado. A dor crônica é minimizada, mas continua a perturbar o sujeito, trata-se de uma dor psíquica.

O psicólogo ao dar possibilidade de vazão à dor física, outras dores transbordam para o campo da palavra e da linguagem, do choro, do silêncio, como formas de elaborar e simbolizar o momento doloroso que estes sujeitos vivem. Ou seja, a dor física não está sozinha e somente encarnada no corpo de quem a sente.

Observou-se, ao longo da pesquisa, que o fenômeno da dor transcende os tecidos e as conexões neuronais de quem a sofre e adentra na existência do sujeito, inunda o psiquismo e reverbera sempre que convocada. A dor física nunca está só: com ela, as reminiscências de outras dores vividas pelo sujeito retomam o presente e isso nos fez pensar em um dado muito delicado sobre o fenômeno da dor, que é justamente o que a literatura aponta sobre a indissociabilidade da dor física e da dor psíquica. Não se separam por serem uma unicidade composta de várias facetas.

As limitações que o câncer causou, em ambas as participantes, dores inestimáveis, situação em que Ana recorre à espiritualidade para minimizar sua angústia e sentir-se confortada no colo de um Deus e Elis tenta sorrir para que esse momento seja menos doloroso. E, neste ponto, conseguimos alcançar outro objetivo específico: identificar quais os recursos de enfrentamento que elas utilizaram para viver este processo. Negar a dor foi um modo que o psiquismo de Elis deu conta naquele momento que vivera.

Frente a delicadeza e o desafio de ser psicólogo, foi possível concluir, também, a importância deste profissional para escutar pacientes que estão em tratamento paliativo e que apresentam dor crônica. Há muito o que se falar diante da dor, das perdas ocasionadas pelo adoecimento e das fantasias relacionadas à morte e ao morrer. Com sua presença continente, o objetivo do psicólogo é proporcionar um ambiente seguro e confortável para que o sujeito se sinta acolhido e à vontade para trazer à tona suas demandas psíquicas, seja por meio da fala, seja pelo silêncio ou pelo corpo. $\mathrm{O}$ sujeito, com sua subjetividade e singularidade, se coloca no lugar de agente de sua própria 
história, revivendo ou não suas dores, rememorando seu passado ou sonhando com um futuro que não seja sua finitude, mas a recuperação da saúde.

Menciona-se a delicadeza, pela sensibilidade na escuta que é preciso ter para acolher a pessoa, com suas peculiaridades e questionamentos. Fala-se de desafio, frente uma sociedade medicalocêntrica, que apresenta uma tendência em abafar os sintomas, anestesiar as dores e produzir sorrisos e saúde pela medicalização para que estejamos todos em um mundo sem sofrimento. A proposta não é diminuir a importância das medicações e analgesias. Pelo contrário, acredita-se que, quanto mais comunicação houver entre a equipe que medica e a equipe que escuta a dor irremediável - que é a dor psíquica -, maior capacidade de simbolização terá o sujeito acometido pela dor crônica e suas nuances e melhor será sua qualidade de vida, pois atravessará o momento doloroso não tão sozinho.

\section{Referências}

Barbosa, L. N. F., \& Francisco, A. L. (2007). A subjetividade do câncer na cultura: implicações na clínica contemporânea. Revista Sociedade Brasileira Psicologia Hospitalar, 10(1), 09-24.

Bardin, L. (2011). Análise de conteúdo. São Paulo: Edições 70.

Berlinck, M. T. (2011). Morte sem futuro e morte com futuro. A questão do tempo na morte. Revista Latinoamericana de Psicopatologia Fundamental, 4(3), 419-25.

Breitbart, W. (2004). Espiritualidade e sentido nos cuidados paliativos. In L Pessini, \& L. Bertachini. (Orgs.). Humanização e Cuidados Paliativos (pp. 209227). São Paulo: Edições Loyola.

Carvalho, M. M. M. J. (2002). O sofrimento da dor em câncer. In M. M. M. J. de Carvalho. (Org.). Introducão à Psicooncologia (pp. 32-45). São Paulo, SP: Livro Pleno.

Castro-Arantes, J. de M., \& Lo Bianco, A. C. (2013). Corpo e finitude - a escuta do sofrimento como instrumento de trabalho em instituição oncológica. Ciência e Saúde Coletiva. 18 (9), 2515-2522.

Dantas, O. M. S. (2013). A primeira e a última dor. Estudos de Psicanálise. 39, 81-84.

Faria, J. B. de, \& Seidl, E. M. F. (2005). Religiosidade e enfrentamento em contextos de saúde e doença: revisão de literatura. Psicologia: reflexão e crítica, 18(3), 381-389.

Ferreira, A. P. de Q., Lopes, L. Q. F., \& Melo, M. C. B. de. (2011). O papel do psicólogo na equipe de cuidados paliativos junto ao paciente com câncer. Revista Sociedade Brasileira Psicologia Hospitalar, 14(2), 85-98.

Freud, S. (2010). Considerações atuais sobre a guerra e a morte. In Obras Completas de Sigmund Freud. Introdução ao narcisismo, ensaios de metapsicologia e outros textos (pp. 209-246). São Paulo: Companhia das Letras.

Fuchs, S. S., \& Zorning, S. (2013). A escuta analítica: corpo, afeto e palavra. Psicologia em Revista, 19(3), 340-52.
Graner, K. M., Junior, A. L. C., \& Rolim, G. S. (2010). Dor em oncologia: intervenções complementares e alternativas ao tratamento medicamentoso. Temas em Psicologia, 18(2). 345-55.

Guimarães, S. S. (1999). Introdução ao estudo da dor. In M. M. M. J. de. Carvalho (org.). Dor: um estudo multidisciplinar. São Paulo, SP: Summus,

INCA - Instituto Nacional do Câncer. (2015). Cuidados Paliativos. (2015). Retirado de http://www1.inca.gov.br/conteudo_view.asp?ID=474

Kovács, M. J. (2003). Educação para a morte: temas e reflexões. São Paulo: Casa do Psicólogo.

Kübler-Ross, E. (2008). Sobre a morte e o morrer: o que os doentes terminais têm para ensinar a médicos, enfermeiras, religiosos e aos seus próprios parentes. São Paulo: Editora WMF Martins.

Miceli, A. V. P. (2002). Dor crônica e subjetividade em oncologia. Revista Brasileira de Cancerologia, 43(8), 363-73.

Miceli, A. V. P. (2014). A comunicação médico-paciente da dor total no câncer. In A. G. Portnoi. (Org.). A psicologia da dor (pp. 77-90). São Paulo: Guanabara Koogan,

Minayo, M. C. S., \& Sanches, O. (1993). Quantitativo-Qualitativo: oposição ou complementaridade? Caderno de Saúde Pública, 9(3), 239-262.

Minayo, M. C. de S. (2014). O desafio do conbecimento: pesquisa qualitativa em saúde. São Paulo: Hucitec.

Naime, F. F. (2013). Manual de tratamento da dor: dor aguda e dor de origem oncológica: tratamento não invasivo. São Paulo: Manole.

Nasio, J. D. (2008). A dor física: uma teoria psicanalitica da dor corporal. Rio de Janeiro: Zahar.

Pessini, L. (2004a). Humanização da dor e do sofrimento humanos na área da saúde. In L. Pessini, \& L. Bertachini. (Orgs.). Humanização e Cuidados Paliativos (pp. 11-28). São Paulo, SP: Edições Loyola.

Pimenta, C. A. de M., Koizumi, M. S., \& Teixeira, M. J. (1997). Dor, depressão e conceitos culturais. Arquivo de Neuropsiquiatria, 55(3), 370-80.

Pinto, E. B. (2004). A pesquisa qualitativa em psicologia clínica. Psicologia USP, 15(1), 71-80.

Salgado, J. V., \& Salgado, J. A. (2013). Introdução à história da dor. In F. F. Naime. (Org.). Manual de tratamento da dor: dor aguda e dor de origem oncológica: tratamento não invasivo (pp. 1-7). São Paulo: Manole.

Santana, J. J. R. A. de, Zanin, C. R., \& Maniglia, J. V. (2008). Pacientes com câncer: enfrentamento, rede social e apoio social. Paidéia, 18(40). 371-84.

Saunders, C. M. (1967). The Management of terminally illness. London: Hospital Medicine Publications.

Simonetti, A. (2011). Manual de Psicologia hospitalar: o mapa da doença. São Paulo: Casa do Psicólogo.

SBED - Sociedade Brasileira para o Estudo da Dor. (2015). O que é Dor. Retirado de http://www.dor.org.br/publico/o-que-e-dor.

Teixeira, M. J., Figueiró, J. A. B., Yeng, L. T., \& Pimenta, C. A. M. (1999). Tratamento multidisciplinar do doente com dor. In M. M. M. J. de Carvalho. (Org.). Dor: um estudo multidisciplinar (pp. 38-52). São Paulo, SP: Summus.

Thomaz, A. (2010). Dor oncológica: conceitualização e tratamento farmacológico. Onco \&. 24-9.

Veit, C. M., \& Castro, E. K. de. (2013). Coping religioso/espiritual e câncer de mama: uma revisão sistemática da literatura. Psicologia, Saúde \& Doenças, 14(1), 1-22.

WHO - World Health Organization. (2002). National cancer control programmes: policies and managerial guidelines. Geneve: OMS.

Submetido em: 10-7-2018

Aceito em: 26-7-2018 